\title{
Synthesis, Characterization and Corrosion Protection Properties of Imidazole Derivatives on Mild Steel in 1.0 M HCl
}

\author{
O. Krim,,${ }^{a}$ O. Krim,${ }^{b, *}$ M. Messali, ${ }^{c}$ B. Hammouti, ${ }^{a}$ A. Elidrissi, ${ }^{a}$ \\ K. Khaled, ${ }^{d}$ R. Salghi ${ }^{e}$ and H. Lgaz ${ }^{e}$ \\ ${ }^{a}$ LCAE-URAC18, Faculté des Sciences, Université Mohammed Premier, B.P. 717, 60000 \\ Oujda, Morocco \\ ${ }^{b}$ Department of Chemistry, An-Najah National University, P.O. Box 7, Nablus, Palestine \\ ${ }^{c}$ Chemistry Department, Faculty of Science, Taibah University, 30002, Al-Madinah Al- \\ Mounawwara, Saudi Arabia \\ ${ }^{d}$ Department of Chemistry, King Saud University, P.O. Box 2455, Riyadh 11451, Saudi Arabia \\ ${ }^{e}$ Laboratory of Environmental Engineering and Biotechnology, ENSA, Université Ibn Zohr, \\ PO Box 1136, 80000 Agadir, Morocco
}

Received 31 March 2016; accepted 20 April 2016

\begin{abstract}
1-(2-Dodecylsulfanyl-ethyl)-1H-imidazole (DSEIm) and 2-Imidazol-1-yl-ethylsulfanyl)-acetic acid (ImESAA) were synthesized via radical catalysis method and characterized using ${ }^{1} \mathrm{H}$ NMR and ${ }^{13} \mathrm{C}$ NMR spectroscopy. The corrosion performances of mild steel specimens were studied by three imidazole derivatives include: 1vinylvinylimidazole (VyIm), DSEIm and ImESAA, which were investigated in $1.0 \mathrm{M}$ $\mathrm{HCl}$ using weight loss measurements, potentiodynamic polarization and electrochemical impedance spectroscopic (EIS) method. The results obtained show that DSEIm is the best corrosion inhibitor; its inhibition efficiency (E \%) increases with increasing the inhibitor concentration, but decreases with the raise of temperature. Potentiodynamic polarization studies clearly revealed that the inhibitors changed the mechanism of hydrogen evolution, and that they acted as mixed inhibitors, but most effectively in the cathodic range. The higher values of activation energy (Ea) in the inhibited solution can be correlated with the increased thickness of the double layer; this is interpreted with physical adsorption of the inhibitor onto the metal surface resulting in the formation of a surface film. Adsorption of imidazole derivatives have been studied with Monte Carlo simulations.
\end{abstract}

Keywords: Adsorption, Aluminium, Corrosion Inhibition, Cefuroxime axetil, SEM.

\footnotetext{
* Corresponding author. E-mail address: sjodeh@ hotmail.com
} 


\section{Introduction}

The phenomenon of corrosion in mild steel represents a fundamental problem both in basic research in industry. The prevention of corrosion is vital not only for increasing the lifetime of equipment, but also in decreasing the dissolution of toxic metals from the components into the environment [1]. Mild steel is one of the most widely used materials of construction. Corrosion of mild steel has an enormous economic impact. The understanding of the corrosion problem and the solution to tackle it is a very active field of research. In corrosion of mild steel, acids like $\mathrm{HCl}$ and $\mathrm{H}_{2} \mathrm{SO}_{4}$ are the most important pickling acids, which are widely used in steel and ferrous alloy industry [2].

However, the main problems in using mild steel in these applications are due to the uniform corrosion attack. At this juncture, there is a need to improve the corrosion performance of mild steel. This can be achieved by adding appropriate concentrations of the organic compounds as inhibitors.

The effect of organic compounds containing heteroatoms on the corrosion behavior of iron and steel in acidic solutions has been recognized for a long time [3-7].

Most of the effective organic corrosion inhibitors contain multiple bonds and heteroatoms such as oxygen, nitrogen, sulfur, with which the inhibitors can adsorb on the metal surface [8-11]; well-known inhibitors are benzaldehydes [12], furans [13], isoxazolidines [14,15], triazoles [16-20], pyridines [21-23], thiadiazole [24,25], oxadiazoles [26], and imidazolines [27-30]. As expected, the physical/chemical adsorption of the inhibitor at the metal surface is influenced by various factors including electron density and л-character of donor atom, types of functional groups, steric effect, etc., [11, 12].

Moreover, nitrogen-containing heterocyclic compounds are considered to be effective corrosion inhibitors [7]. Among these, imidazole and its derivatives have been found to be the most effective and widely used organic compounds for corrosion inhibition of mild steel in acid medium [31-32] due to the presence of the electron donating heteroatom namely, nitrogen. In addition, the compounds containing both nitrogen and sulphur can provide excellent inhibition compared with compounds containing only nitrogen or sulphur [33-35]. Their adsorption is generally explained by the formation of an adherent film on the metal surface [36].

Despite several experimental and computational tools that have been designed to study the structural characteristics of the inhibitor molecules, little is known about the interaction between the adsorbed inhibitor molecules and the corroding metal surface. A practical route to study these complex processes is computer simulations using suitable models [37-38].

In continuation of our effort in developing corrosion inhibitors with high effectiveness and efficiency, the present paper describes the synthesis of imidazole derivatives using radical catalyzed addition of mercaptoacetic acid and 1-dodecanethiol to 1-vinylvinylimidazole, as described elsewhere [39-41]. The properties of these compounds, DSEIm and ImESAA, as corrosion inhibitors for mild steel in molar $\mathrm{HCl}$ were studied by gravimetry, potentiokinetic polarization, 
electrochemical impedance spectroscopy (EIS) and Monte Carlo simulation methods.

\section{Materials and methods}

\section{Materials}

The chemical composition (wt.) of the mild steel used in the present study was 0.09 wt. \% P, 0.38 wt.\% Si, 0.01 wt.\% Al, 0.05 wt.\% Mn, 0.21 wt.\% C, 0.05 wt.\% $\mathrm{S}$. The mild steel specimens were mechanically grounded and polished using different grades of abrasive $\mathrm{SiC}$ papers, then washed with distilled water, degreased with acetone and subsequently dried at room temperature. Corrosion media were prepared from $\mathrm{HCl}$ and double-distilled water.

\section{Synthesis}

Initially, 1-(2-Dodecylsulfanyl-ethyl)-1H-imidazole (DSEIm) was synthesized according to a previously reported procedure using the method of telomerization $[39,40]$. In a $250 \mathrm{~mL}$ three-necked flask equipped with a condenser and a nitrogen flux, $18.6 \mathrm{~g}\left(9.210^{-2} \mathrm{~mol}\right)$ of 1-dodecanethiol dissolved in $100 \mathrm{~mL}$ of acetonitrile was introduced. A solution containing $4 \mathrm{~g}\left(4.210^{-2} \mathrm{~mol}\right)$ of 1 vinylimidazole (VyIm) and $0.07 \mathrm{~g}\left(4.210^{-4}\right.$ mole $)$ of azobisisobutyronitrile $(\mathrm{AIBN})$ as initiator was then added dropwise. The mixture was stirred and heated using oil bath at $353 \mathrm{~K}$ under a continuous flow of nitrogen for $3 \mathrm{~h}$.

The solvent and excess thiol were then evaporated off under vacuum and the product isolated by trituration with methanol. The crude sample was purified by column chromatography on silica using ethyl acetate as eluent, giving the final monoadduct as a viscous orange liquid in $84 \%$ yield.

The reaction with mercaptoacetic acid was realized under the same conditions using $4 \mathrm{~g}\left(4.210^{-2} \mathrm{~mol}\right)$ of 1-vinylimidazole, $8.8 \mathrm{~g}\left(9.210^{-2} \mathrm{~mol}\right)$ of mercaptoacetic acid, and $0.07 \mathrm{~g}\left(4.210^{-4} \mathrm{~mol}\right)$ of AIBN.

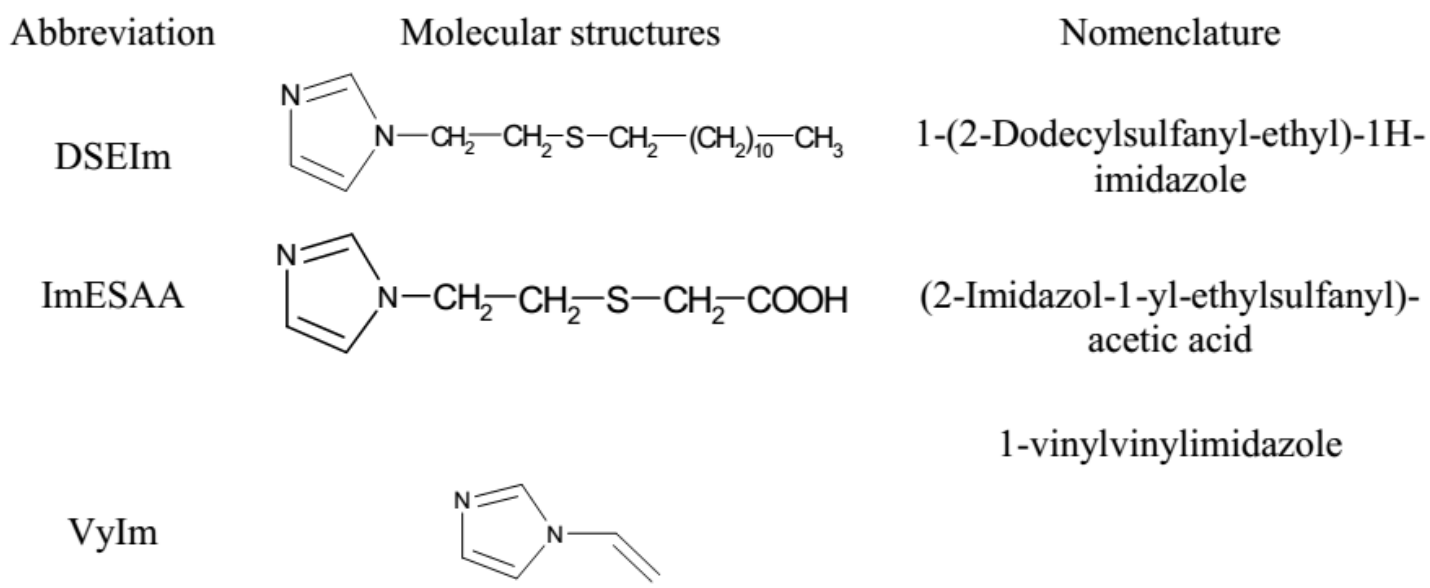

Figure 1. Molecular structures of imidazole derivatives. 
The monoadduct, (2-Imidazol-1-yl-ethylsulfanyl)-acetic acid (ImESAA) was again obtained as a viscous, orange liquid (yield 91\%). Molecular structures of DSEIm and ImESAA were presented in Fig.1.

The characterization of DSEIm and ImESAA was performed using ${ }^{1} \mathrm{H}$ NMR and ${ }^{13} \mathrm{C}$ NMR recorded for $\mathrm{CDCl}_{3}$ solutions with tetramethylsilane (TMS) as reference. The letters $\mathrm{s}, \mathrm{d}, \mathrm{t}, \mathrm{q}$, and $\mathrm{m}$ denote respectively singlet, doublet, triplet, quadruplet, and multiplet.

\section{Measurements}

\section{Weight loss technique}

Gravimetric experiments were carried out in a double-walled glass cell. The test pieces were cut nearly $(1.5 \mathrm{~cm} \times 1.5 \mathrm{~cm} \times 0.04 \mathrm{~cm})$, weighed and suspended in the test solution $(1.0 \mathrm{M} \mathrm{HCl})$ with and without the addition of inhibitors at a temperature of $308 \mathrm{~K}$ in air atmosphere without bubbling.

After specified periods of time $(6 \mathrm{~h})$, the test pieces were taken out of the test solution, rinsed in doubly distilled water, dried as before and weighed again.

\section{Polarization measurements}

Stainless steel strips with an exposed area of $1 \mathrm{~cm}^{2}$ were used. Measurements were carried out in a standard glass three-electrode electrolysis cylindrical Pyrex glass cell. The auxiliary and the reference electrodes are platinum and saturated calomel (SCE), respectively. 352 Soft CorrTM III software was used to control an EG\&G Instruments potentiostat-galvanostat model $263 \mathrm{~A}$ at a scan rate of 20 $\mathrm{mV} / \mathrm{min}$. The working electrode was initially kept at the corrosion potential for $30 \mathrm{~min}$ before recording the cathodic curves up to the $-800 \mathrm{mV}$. The test solutions were de-aerated with pure nitrogen and the flow was maintained throughout the experiments. The inhibition efficiency E\% was calculated using the following equation:

$$
\mathrm{E} \%=\frac{\mathrm{I}_{\text {corr }}^{0}-\mathrm{I}_{\text {corr }}}{\mathrm{I}_{\text {corr }}^{0}} \times 100
$$

where $I_{\text {corr }}$ and $I_{\text {corr }}^{0}$ are the corrosion current densities of mild steel in the presence and absence of inhibitor, respectively.

\section{Electrochemical impedance spectroscopy (EIS)}

EIS experiments were conducted using computer controlled simulations with a Tacussel electrochemical system for calculation of polarization resistance (Rp) and double layer capacitance $\left(\mathrm{C}_{\mathrm{dl}}\right)$ values. All experiments were performed with a frequency ranging from $100 \mathrm{mHz}$ to $10 \mathrm{kHz}(10 \mathrm{mV}$ peak-to-peak). The impedance diagrams were plotted in the Nyquist representation. The inhibition efficiency $E_{\mathrm{w}}$ was calculated using the following equation:

$$
\mathrm{E}_{\mathrm{W}} \%=\frac{\mathrm{W}_{\text {corr }}^{0}-\mathrm{W}_{\text {corr }}}{\mathrm{W}_{\text {corr }}^{0}} \times 100
$$

where $\mathrm{W}_{\text {corr }}$ and $\mathrm{W}_{\text {corr }}^{0}$ are the corrosion rates of mild steel in the absence and presence of the inhibitor, respectively. 


\section{Results and Discussion}

\section{Characterization}

Characterization of DSEIm

${ }^{1} \mathrm{H}$ NMR spectrum of DSEIm, Fig. 2, shows two new triplets at $(\delta 2.38,2.82)$ assigned to the methylene groups adjacent to sulfur, and the absence of three signals at 4.7, 5.1 and 6.8 confirms the loss of the vinyl unit.

The proton decoupled ${ }^{13} \mathrm{C}$ NMR spectrum of DSEIm was also used to examine the chemical structure of the monoadduct and it is shown in Fig. 3. The signals at 177.05 and $175.34 \mathrm{ppm}$ were due to the adjacent carbons to sulfur atom of the monomer.
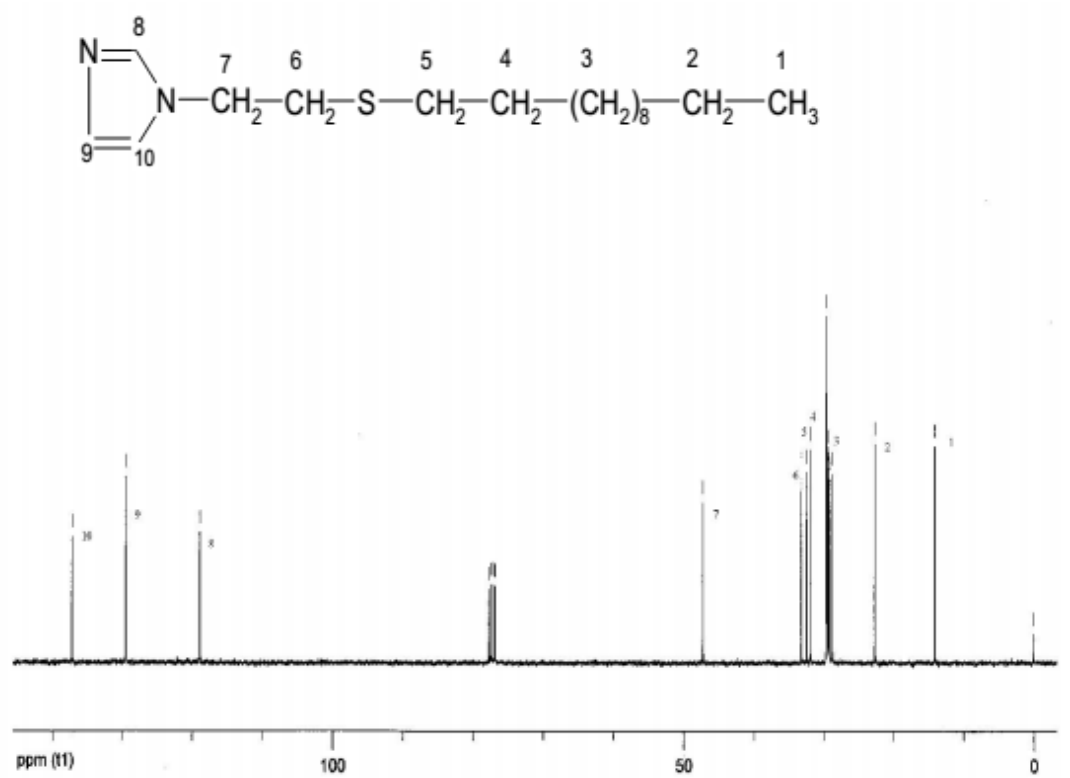

Figure 2. ${ }^{1} \mathrm{H}$ NMR spectrum $\left(\mathrm{CDCl}_{3}\right)$ of 1-(2-Dodecylsulfanyl-ethyl)-1H-imidazole (DSEIm).
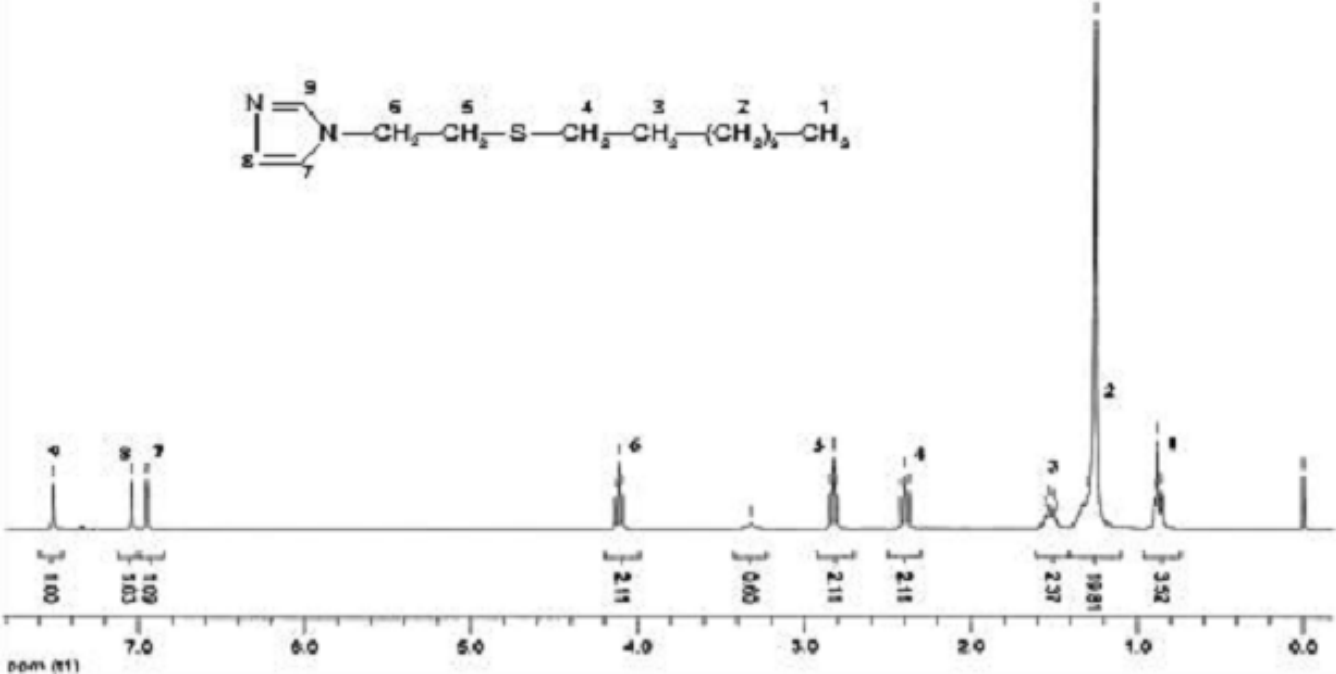

Figure 3. ${ }^{13} \mathrm{C}$ NMR spectrum $\left(\mathrm{CDCl}_{3}\right)$ of 1-(2-Dodecylsulfanyl-ethyl)-1H-imidazole (DSEIm). 
Characterization of ImESAA

${ }^{1} \mathrm{HNMR}\left(\mathrm{CDCl}_{3} / \mathrm{TMS}\right): 2,92(\mathrm{t}, 2 \mathrm{H}) ; 3,38(\mathrm{~s}, 2 \mathrm{H}) ; 4,10(\mathrm{t}, 2 \mathrm{H}) ; 6,97(\mathrm{~d}, 1 \mathrm{H})$;

$7,01(\mathrm{~d}, 1 \mathrm{H}) ; 7,54(\mathrm{~s}, 1 \mathrm{H})$

${ }^{13} \mathrm{CNMR}\left(\mathrm{CDCl}_{3}\right): 32,3 ; 38 ; 49,4 ; 122,6 ; 125,5 ; 138,6 ; 177$

\section{Inhibitive effect of imidazole derivatives}

Gravimetric measurements

The effect of the addition of VyIm, DSEIm and ImESAA at different concentrations on the corrosion of mild steel in $1.0 \mathrm{M} \mathrm{HCl}$ solution was studied by measuring the weight loss after $6 \mathrm{~h}$ of immersion. Table 1 gathers the values deduced for $\mathrm{W}_{\text {corr }}$ and $\mathrm{E} \%$.

Gravimetric measurements showed that the corrosion decreased in the presence of VyIm, ImESAA and DSEIm. The inhibition efficiency increased with the inhibitor's concentration to reach $95 \%$ for DSEIm, $86.5 \%$ for ImESAA and $75.5 \%$ for VyIm at $10^{-3} \mathrm{M}$ (Table 1). Thus, all derivatives studied inhibited the corrosion, but DSEIm was the most effective.

Table 1. Gravimetric results of mild steel in $1.0 \mathrm{M} \mathrm{HCl}$ at $308 \mathrm{~K}$ without and with different inhibitor concentrations.

\begin{tabular}{|c|c|c|c|}
\hline \multirow[t]{2}{*}{ Structure of inhibitors } & Concentration (M) & $W_{\text {corr }}\left(\mathrm{mg.cm}^{-2} \cdot \mathrm{h}^{-1}\right)$ & $\mathrm{Ew}_{\mathrm{W}}(\%)$ \\
\hline & Blank & 1.1 & - \\
\hline \multirow{6}{*}{$\left(\mathrm{C}_{5} \mathrm{H}_{6} \mathrm{~N}_{2} ; \mathrm{M}=94,1 \mathrm{~g} \cdot \mathrm{mol}^{-1}\right)$} & $10^{-3}$ & 0.270 & 75.5 \\
\hline & $5 \times 10^{-4}$ & - - - & - - - \\
\hline & $10^{-4}$ & 0.505 & 54.1 \\
\hline & $5 \times 10^{-5}$ & - . - & - . - \\
\hline & $10^{-5}$ & 0.707 & 35.7 \\
\hline & $10^{-6}$ & 0.826 & 24.9 \\
\hline \multirow[t]{2}{*}{ DSEIm } & $10^{-3}$ & 0.055 & 95.0 \\
\hline & $5 \times 10^{-4}$ & 0.128 & 88.4 \\
\hline \multirow{2}{*}{$\mathrm{N}-\mathrm{CH}_{2}-\mathrm{CH}_{2}-\mathrm{S}-\mathrm{CH}_{2}-\left(\mathrm{CH}_{2}\right)_{10}-\mathrm{CH}_{3}$} & $10^{-4}$ & 0.241 & 78.1 \\
\hline & $5 \times 10^{-5}$ & 0.273 & 75.2 \\
\hline \multirow[t]{2}{*}{$\left(\mathrm{C}_{17} \mathrm{H}_{32} \mathrm{~N}_{2} \mathrm{~S} ; \mathrm{M}=296,5 \mathrm{~g} \cdot \mathrm{mol}^{-1}\right)$} & $10^{-5}$ & 0.497 & 54.8 \\
\hline & $10^{-6}$ & 0.708 & 35.6 \\
\hline \multirow{6}{*}{$\begin{array}{l}\text { ImESAA } \\
\left(\mathrm{C}_{7} \mathrm{H}_{10} \mathrm{~N}_{2} \mathrm{O}_{2} \mathrm{~S} ; \mathrm{M}=186,2 \mathrm{~g} \cdot \mathrm{mol}^{-1}\right)\end{array}$} & $10^{-3}$ & 0.149 & 86.5 \\
\hline & $5 \times 10^{-4}$ & 0.213 & 80.6 \\
\hline & $10^{-4}$ & 0.332 & 69.8 \\
\hline & $5 \times 10^{-5}$ & 0.427 & 61.2 \\
\hline & $10^{-5}$ & 0.510 & 53.6 \\
\hline & $10^{-6}$ & 0.602 & 45.3 \\
\hline
\end{tabular}

\section{Polarization curves}

Anodic and cathodic polarization curves for mild steel in $1.0 \mathrm{M} \mathrm{HCl}$ with and without various concentrations of the inhibitors are shown in Fig. 4, 5 and 6. Values of the corrosion potential ( $\left.\mathrm{E}_{\text {corr }}\right)$, corrosion current density ( $\left.\mathrm{I}_{\text {corr }}\right)$, and the inhibition efficiency (E\%) were determined by the Tafel extrapolation method, and are given in Table 2.

Addition of the various inhibitors decreased $\mathrm{I}_{\text {corr }}$ significantly for all the studied concentrations, due to the increase in the fraction of the electrode surface blocked by adsorption. The cathodic current versus potential curves gave rise to Tafel lines indicating that the hydrogen evolution reaction was activation controlled, $\mathrm{b}_{\mathrm{c}}$ 
values being slightly modified, and due to modification of the mechanism of the proton discharge reaction.

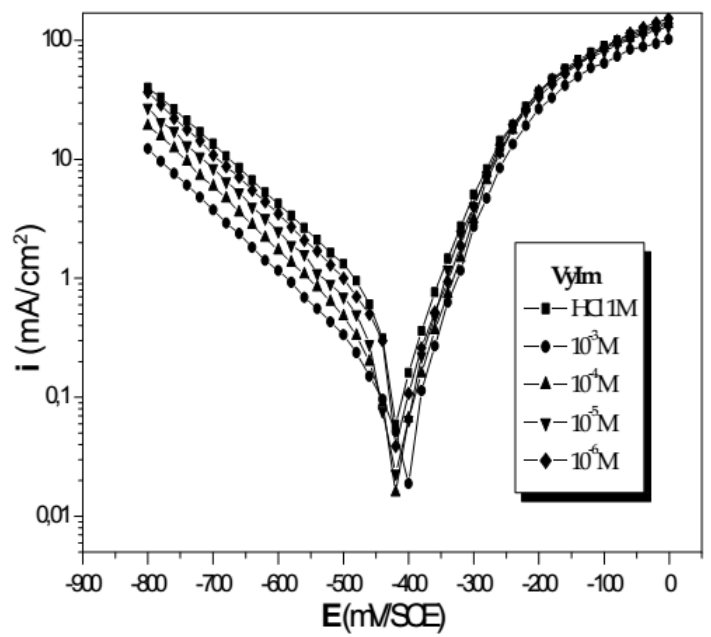

Figure 4. Polarization curves of mild steel in $1.0 \mathrm{M} \mathrm{HCl}$ in the absence and the presence of different concentrations of VyIm.

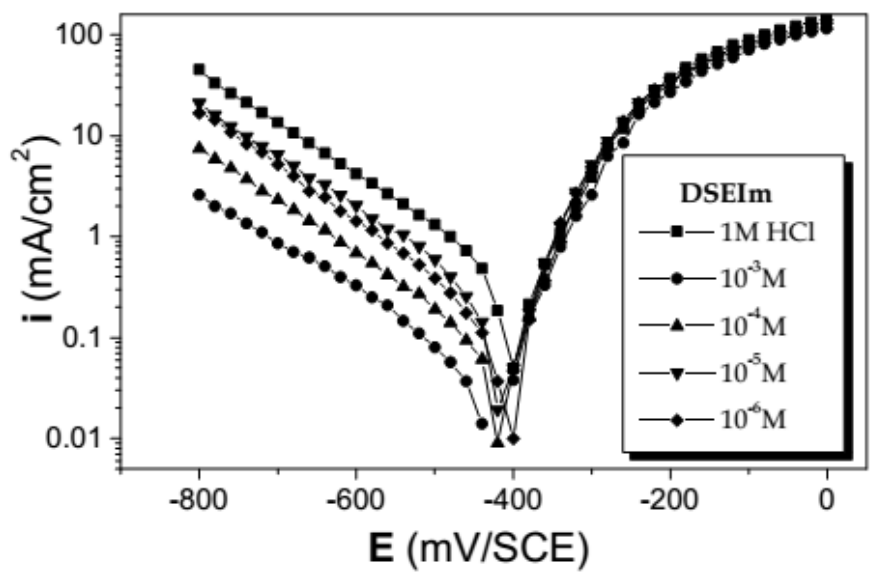

Figure 5. Polarization curves of mild steel in $1.0 \mathrm{M} \mathrm{HCl}$ in the absence and in the presence of different concentrations of DSEIm.

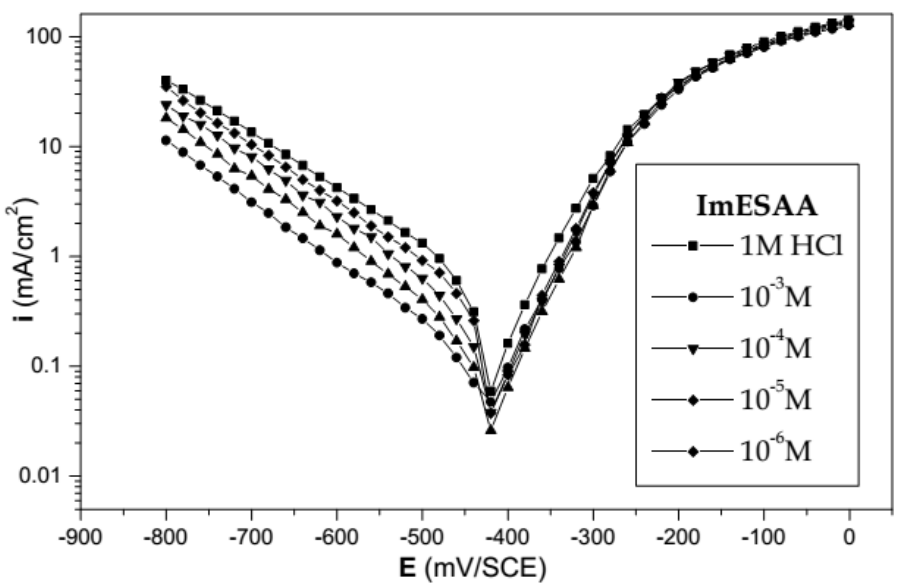

Figure 6. Polarization curves of mild steel in $1.0 \mathrm{M} \mathrm{HCl}$ in the absence and in the presence of different concentrations of ImESAA. 
The anodic branches were only slightly affected in the presence of these inhibitors, the highest effect being observed with DSEIm. The inhibitors thus act as mixed inhibitors, but predominantly in the cathodic domain. The long side chain of DSEIm slightly, $-\mathrm{S}-\left(\mathrm{CH}_{2}\right)_{11}-\mathrm{CH}_{3}$, presumably plays a major role in the adsorption, and the presence of the acid function $-\mathrm{S}-\mathrm{CH}_{2} \mathrm{COOH}$ in ImESAA must diminish the inhibition protection [42].

\section{Electrochemical impedance spectroscopic studies}

Fig. 7 presents the Nyquist diagrams obtained in the absence and the presence of DSEIm at different concentrations. The impedance parameters calculated are given in Table 3 . The charge-transfer resistance values $\left(R_{c t}\right)$ were calculated from the difference in impedance at lower and higher frequencies [42] .To obtain the double-layer capacitance $\left(\mathrm{C}_{\mathrm{dl}}\right)$, the frequency $\mathrm{f}_{\max }$ at which the imaginary component of the impedance is maximum (-Zimax) was found, and $\mathrm{C}_{\mathrm{dl}}$ values were obtained from the following equation:

$$
\mathrm{C}_{\mathrm{dl}}=\frac{1}{2 \pi f_{\max } \mathrm{R}_{\mathrm{t}}}
$$

In this case, the inhibition efficiency was calculated using the charge transfer resistance from:

$$
\mathrm{E}_{\mathrm{z}} \%=\frac{\mathrm{W}_{\mathrm{t} \text { (inh) }}-\mathrm{W}_{\mathrm{t}}}{\mathrm{W}_{\mathrm{t} \text { (inh) }}} \times 100
$$

where Rt(inh) and Rt are the charge transfer resistance in the presence and absence of DSEIm, respectively.

Table 2. Electrochemical parameters of mild steel in $1.0 \mathrm{M} \mathrm{HCl}$ at $308 \mathrm{~K}$, without and with different inhibitor concentrations.

\begin{tabular}{|c|c|c|c|c|c|}
\hline Inhibitor & $\begin{array}{c}\text { Concentration } \\
(\mathbf{M})\end{array}$ & $\begin{array}{c}\text { Ecorr } \\
(\mathbf{m V}) / \mathbf{S C E}\end{array}$ & $\begin{array}{c}\text { Icorr } \\
\left(\boldsymbol{\mu} \mathbf{A c m}^{-2}\right)\end{array}$ & $\begin{array}{c}\text { bc } \\
\left(\mathbf{m V ~ d e c}^{\mathbf{- 1}}\right)\end{array}$ & $\begin{array}{c}\mathbf{E} \\
(\boldsymbol{\%})\end{array}$ \\
\hline \multirow{3}{*}{ VyIm } & Blank & -433 & 660 & 191.9 & - \\
& $10^{-3}$ & -420 & 179.5 & 195.8 & 72.8 \\
& $10^{-4}$ & -423 & 320.7 & 194.4 & 51.4 \\
& $10^{-5}$ & -428 & 432.3 & 184.1 & 34.5 \\
\hline \multirow{3}{*}{ DSEIm } & $10^{-6}$ & -426 & 508.8 & 189.7 & 22.9 \\
\hline \multirow{4}{*}{ ImESAA } & $10^{-3}$ & -442 & 049.5 & 204.8 & 92.5 \\
& $10^{-4}$ & -423 & 153.7 & 183.0 & 76.7 \\
& $10^{-5}$ & -427 & 306.9 & 190.7 & 53.5 \\
& $10^{-6}$ & -403 & 451.4 & 206.2 & 31.6 \\
\hline & $10^{-3}$ & -425 & 115.5 & 192.6 & 82.5 \\
& $10^{-4}$ & -421 & 219.7 & 194.5 & 66.7 \\
& $10^{-5}$ & -427 & 327.3 & 196.5 & 50.4 \\
& $10^{-6}$ & -426 & 365.6 & 192.8 & 44.6 \\
\hline
\end{tabular}

The results show that $R_{t}$ increased, and $C_{d l}$ tended to decrease when the concentration of the inhibitor increased. A decrease in the Cdl values, which can result from a decrease in the local dielectric constant and/or an increase in the 
thickness of the electrical double layer, suggests that DSEIm functions by adsorption at the metal solution/interface [43].

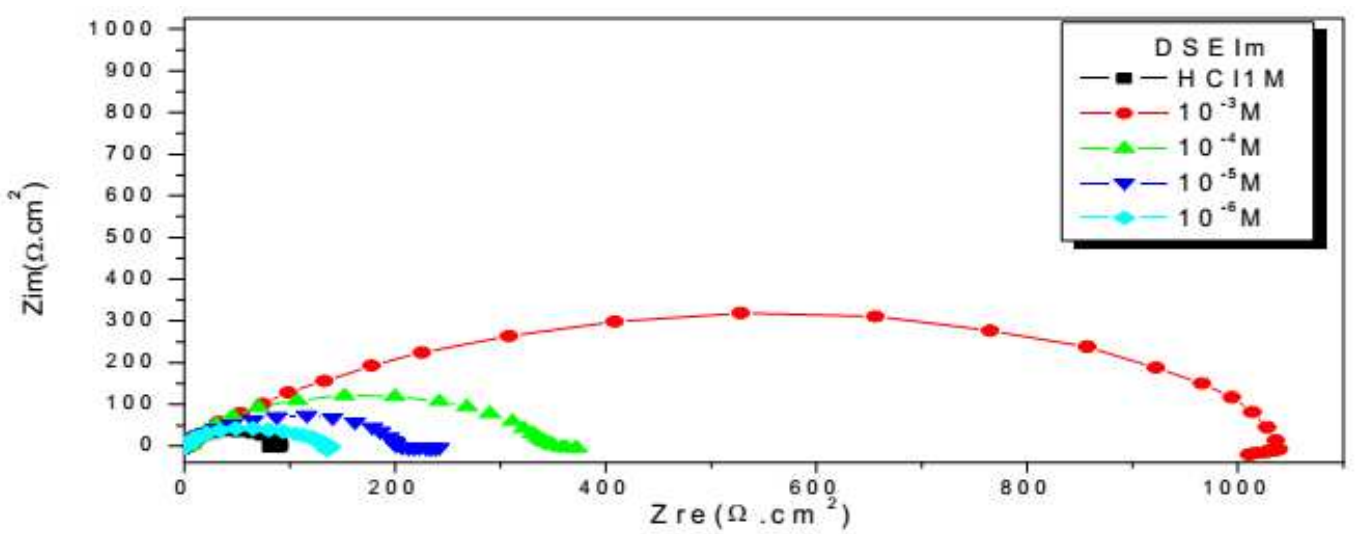

Figure 7. Nyquist plots of mild steel in $1.0 \mathrm{M} \mathrm{HCl}$ in the absence and in the presence of various concentrations of DSEIm.

The high values of inhibition efficiency observed in the case of DSEIm and ImESAA molecules are due to the presence of the sulfur atom and its highest molecular size.

Table 3. Impedance parameters of steel in $1.0 \mathrm{M} \mathrm{HCl}$ at $308 \mathrm{~K}$ in the absence and in the presence of different concentrations of DSEIm.

\begin{tabular}{|c|c|c|c|c|c|}
\hline Structure of inhibitors & $\begin{array}{c}\text { Concentration } \\
(\mathbf{M})\end{array}$ & $\begin{array}{c}\mathbf{R}_{\mathbf{t}} \\
\left(\Omega \cdot \mathbf{c m}^{2}\right)\end{array}$ & $\begin{array}{c}\boldsymbol{f}_{\max } \\
(\mathbf{H z})\end{array}$ & $\begin{array}{c}\mathbf{C}_{\text {dl }} \\
\left(\boldsymbol{\mu} \mathbf{F} / \mathbf{c m}^{2}\right)\end{array}$ & $\begin{array}{c}\mathbf{E}_{\mathbf{W}} \\
(\mathbf{\%})\end{array}$ \\
\hline & Blank & 92 & 25.1 & 68.9 & \\
\hline & $10^{-3}$ & 1022.7 & 7.14 & 26.1 & 91.0 \\
DSEIm & $10^{-4}$ & 358.6 & 10 & 59.4 & 74.3 \\
& $10^{-5}$ & 181.5 & 14.05 & 71.7 & 49.3 \\
& $10^{-6}$ & 122.0 & 15.82 & 84.6 & 24.6 \\
\hline
\end{tabular}

The nitrogen and sulfur atoms are the major adsorption center for their interaction with the metal surface. The extent of inhibition is found to be more for DSEIm than for ImESAA, and efficiency reaches $95 \%$ and $86.5 \%$, respectively at $10^{-3} \mathrm{M}$ (Table 1 ). This difference in the inhibition efficiency is attributed to the presence of an electron donor group of DSEIm $\left(\mathrm{C}_{12} \mathrm{H}_{25}\right)$; this last group increases and enriches the electron density on the sulfur atom and, consequently, increases the density of the molecule (DSEIm) and provides an active adsorption center. On the other hand, the presence of an electron attractor group $(-\mathrm{COOH})$ in the molecule ImESAA decreases its inhibition efficiency.

\section{Effect of temperature}

In acidic media, the corrosion of metal is generally accompanied with the evolution of $\mathrm{H}_{2}$ gas. This is usually followed by an increase in temperature and acceleration of the corrosion reaction which results in higher dissolution rate of the metal [22].

The results retired from Table 4 and Fig. 8 show that DSEIm inhibits the corrosion of steel in $1 \mathrm{M} \mathrm{HCl}$ solution. The corrosion rate was found to depend 
on the concentration of DSEIm and experimental temperature. It is evident from Table 4 and Fig. 8 that the corrosion rate decreased with increasing inhibitor concentration, but increased with a rise in temperature.

Table 4 also shows that inhibition efficiency $(\% \mathrm{E})$ decreased with rise in temperature, and reached its maximum value of $76 \%$ at a concentration of $7.5 \times 10^{-5} \mathrm{M}$. A decrease in inhibition efficiency with an increase in temperature may be due to the desorption of inhibitor molecules at higher temperatures. This has been attributed to physical adsorption of the inhibitor molecule on the mild steel surface [44].

Table 4. Calculated values of the corrosion rate and the inhibition efficiency for mild steel in $1.0 \mathrm{M} \mathrm{HCl}$ in the absence and in the presence of DSEIm at 308-333 K.

\begin{tabular}{|c|c|c|c|c|c|c|c|c|}
\hline \multirow[t]{3}{*}{ Concentration } & \multicolumn{4}{|c|}{ Corrosion rate $\left(\mathrm{mg} \mathrm{cm}^{-2} \mathrm{~h}^{-1}\right)$} & \multicolumn{4}{|c|}{ Inhibition efficiency (\%E) } \\
\hline & 308 & 313 & 323 & 333 & 308 & 313 & 323 & 333 \\
\hline & $(\mathrm{K})$ & $(\mathrm{K})$ & $(\mathrm{K})$ & $(\mathrm{K})$ & $(\mathrm{K})$ & $(\mathrm{K})$ & $(\mathrm{K})$ & $(\mathrm{K})$ \\
\hline Blank & 1.15 & 1.43 & 3.17 & 6.41 & - & - & - & - \\
\hline $1.0 \times 10^{-5}$ & 0.65 & 0.88 & 2.27 & 4.75 & 43 & 38 & 28 & 26 \\
\hline $2.5 \times 10^{-5}$ & 0.41 & 0.71 & 2.05 & 4.46 & 64 & 50 & 35 & 30 \\
\hline $5.0 \times 10^{-5}$ & 0.31 & 0.63 & 1.92 & 3.98 & 73 & 56 & 39 & 38 \\
\hline $7.5 \times 10^{-5}$ & 0.28 & 0.54 & 1.57 & 3.73 & 76 & 62 & 50 & 42 \\
\hline
\end{tabular}

The apparent activation energy, Ea, for the corrosion reaction of mild steel in 1.0 $\mathrm{M} \mathrm{HCl}$ in the presence and the absence of DSEIm was calculated from the Arrheniustype equation:

$$
\log W_{\text {corr }}=A-\frac{E_{a}}{2.303 R T}
$$

where $\mathrm{W}_{\text {corr }}$ is the corrosion rate, $\mathrm{E}_{\mathrm{a}}$ is the apparent activation energy, $\mathrm{R}$ is the molar gas constant $\left(8.314 \mathrm{~J} \mathrm{~K}^{-1} \mathrm{~mol}^{-1}\right), \mathrm{T}$ is the absolute temperature, and $\mathrm{A}$ is the frequency factor.

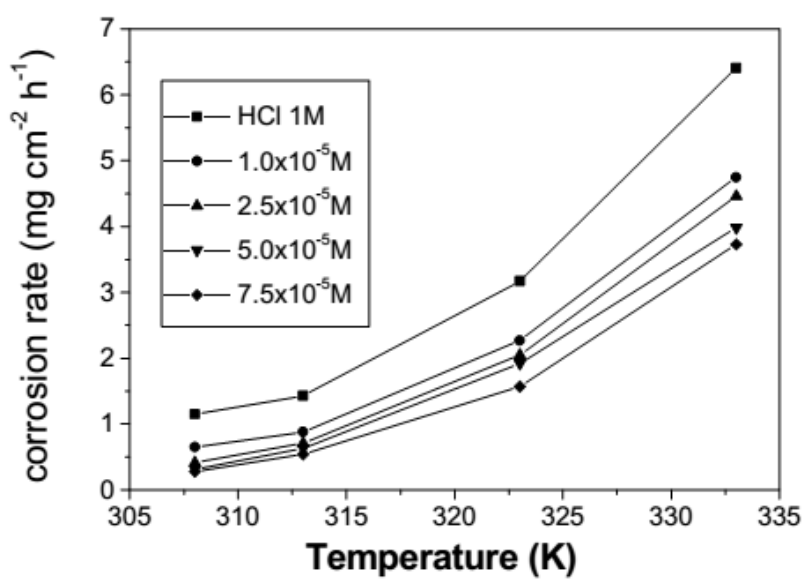

Figure 8. Relationship between corrosion rate and temperature for different concentrations of DSEIm.

For the corrosion of steel in acid medium, the natural logarithm of the corrosion rate $\left(\mathrm{W}_{\text {corr }}\right)$ is a linear function with $1 / \mathrm{T}[45]$. The plot of $\log \mathrm{W}_{\text {corr }}$ against $1 / \mathrm{T}$ for 
mild steel corrosion in $1.0 \mathrm{M} \mathrm{HCl}$ in the absence and presence of different concentrations of DSEIm is presented in Fig. 9.

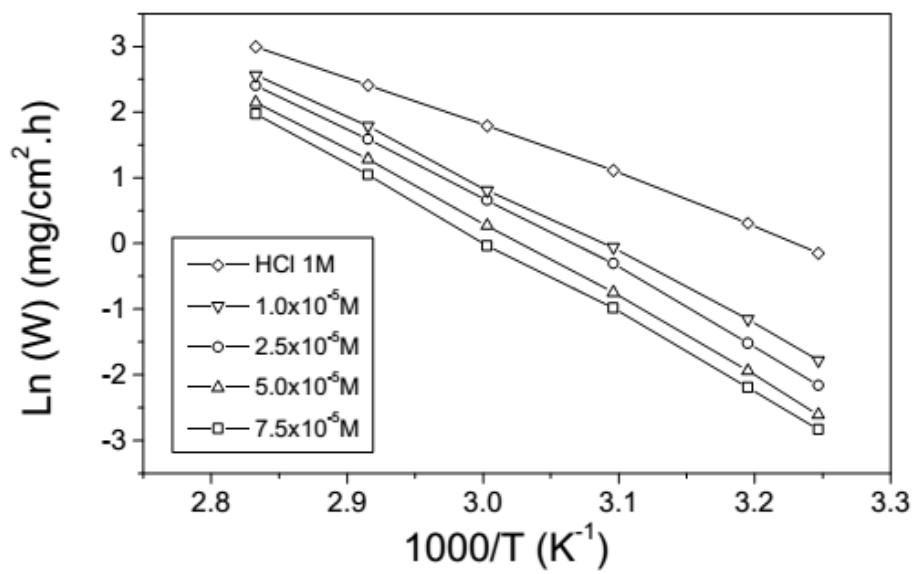

Figure 9. Arrhenius plot for mild steel corrosion in $1.0 \mathrm{M} \mathrm{HCl}$ with and without DSEIm at different concentrations.

The activation energies calculated for $\mathrm{HCl}$ only and in the presence of $1 \times 10^{-5} \mathrm{M}$, $2.5 \times 10^{-5} \mathrm{M}, 5 \times 10^{-5}$ and $7.5 \times 10^{-5} \mathrm{M}$ DSEIm were $53.43 \mathrm{~kJ} \mathrm{~mol}^{-1}, 67.35 \mathrm{~kJ} \mathrm{~mol}^{-1}$, $71.21 \mathrm{~kJ} \mathrm{~mol}^{-1}$ and $84.51 \mathrm{~kJ} \mathrm{~mol}^{-1}$, respectively.

It is observed that the apparent activation energy is higher in the presence of the inhibitor than in its absence.

The higher values of $\mathrm{Ea}$ in the inhibited solution can be correlated with the increased thickness of the double layer, which enhances the activation energy of the corrosion process [46]. This is interpreted with physical adsorption of the inhibitor onto the metal surface, resulting in the formation of a surface film. This type of inhibitor retards the corrosion at ordinary temperatures, but the inhibition is diminished especially at temperatures higher than $313 \mathrm{~K}$ [23].

However, the adsorption phenomenon of an organic molecule is not considered only as a physical or as a chemical adsorption phenomenon, because a wide spectrum of conditions, ranging from the dominance of chemisorption or electrostatic effects may arise due to the complex nature of the corrosion inhibiting process [48].

\section{Monte Carlo simulation adsorption studies}

In the current study, selected imidazole derivatives have been simulated as adsorbates on an iron (Fe) (111) surface substrate to find the low energy adsorption sites and to investigate the preferential adsorption of the studied imidazole derivatives. To calculate the adsorption density as well as the binding energy of the studied inhibitors, the Monte Carlo method has been used. In this computational work, possible adsorption configurations have been identified by carrying out Monte Carlo searches of the configurational space of the iron/imidazole derivatives system as the temperature was gradually decreased. Imidazole derivatives were constructed and their energy was optimized using Forcite classical simulation engine [48-49]. The geometry optimization process is carried out using an iterative process, in which the atomic coordinates are 
adjusted until the total energy of a structure is minimized, i.e., it corresponds to a local minimum in the potential energy surface. Geometry optimization is based on reducing the magnitude of the calculated forces until they become smaller than defined convergence tolerances [50]. The forces on the atoms in the studied inhibitors are calculated from the potential energy expression and will, therefore, depend on the force field that is selected [5].

It was shown from chemical and electrochemical studies that the substitution of the hydrogen atom of amino group (-NH-) of imidazole by different substituents - dodecyl(ethyl)sulfane (DSEIm), ethylsulfanyl acetic acid (ImESAA) and vinyl (vyIm) - leads to an increase of the inhibition efficiency as given in Figures 5-7 and Tables 1-3. Each imidazole derivative contains imidazole ring, and the rest of the molecule can affect adsorption by its influence on the electron density of the side chains. Geometric and electronic structures of the imidazoles were calculated by optimization of their bond lengths and bond angles. The optimized structures are given in Fig. 10.

The molecular dynamic (MD) simulations were performed using the software, Materials Studio [50]. The MD simulation of the interaction between the imidazole derivatives molecules and $\mathrm{Fe}$ (111) surface was carried out in a simulation box $(17.38 \AA \times 17.38 \AA \times 44.57 \AA)$ with periodic boundary conditions to model a representative part of the interface devoid of any arbitrary boundary effects [50]. The Fe (111) was first built and relaxed by minimizing its energy using molecular mechanics, then the surface area of Fe (111) was increased and its periodicity is changed by constructing a super cell, and then a vacuum slab with $15 \AA$ thicknesses was built on the Fe (111) surface [50]. The number of layers in the structure was chosen so that the depth of the surface is greater than the non-bond cutoff used in calculation. Using six layers of iron atoms gives a sufficient depth, so that the inhibitor molecules will only be involved in nonbond interactions with iron atoms in the layers of the surface, without increasing the calculation time unreasonably.

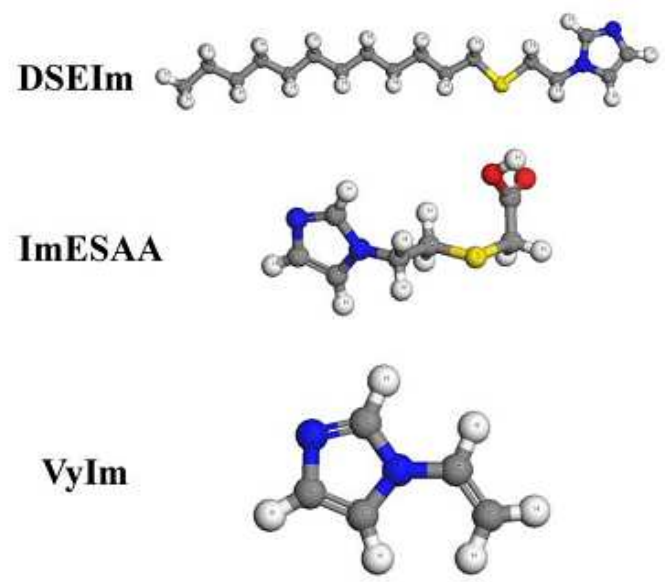

Figure 10. Optimized structures of imidazole derivatives.

This structure is then converted to exhibit 3D periodicity. As 3D periodic boundary conditions are used, it is important that the size of the vacuum slab is enough $(15 \AA)$, and that the non-bond calculation for the adsorbate does not 
interact with the periodic image of the bottom layer of atoms in the surface. After minimizing the $\mathrm{Fe}$ (111) surface and the imidazole derivatives molecules, the corrosion system will be built by a layer builder to place the inhibitor molecules on the Fe (111) surface, and the behaviors of these molecules on the Fe (111) surface are simulated using the COMPASS (condensed phase optimized molecular potentials for atomistic simulation studies) force field. The adsorption locator module in Materials Studio $6.0[50,51]$ has been used to model the adsorption of the inhibitor molecules onto the Fe (111) surface, and therefore provides access to the energy of the adsorption and its effects on the inhibition efficiencies of the studied imidazole derivatives [52-57]. The binding energy between the imidazole derivatives and the Fe (111) surface was calculated using the following equation $[58,59]$ :

$$
\mathrm{E}_{\text {binding }}=\mathrm{E}_{\text {total }}-\left(\mathrm{E}_{\text {surface }}+\mathrm{E}_{\text {inhibitor }}\right)
$$

where $\mathrm{E}_{\text {total }}$ is the total energy of the surface and imidazole derivative, $\mathrm{E}_{\text {surface }}$ is the energy of the surface without the imidazole derivative, and $E_{\text {inhibitor }}$ is the energy of the imidazole derivative without the steel surface.

The Metropolis Monte Carlo method in Adsorption Locator provides four step types for a canonical ensemble: conformer, rotation, translation and re-growth [60]. Fig. 11 shows the most suitable imidazole derivatives conformation adsorbed on Fe (111) substrate obtained by adsorption locator module.
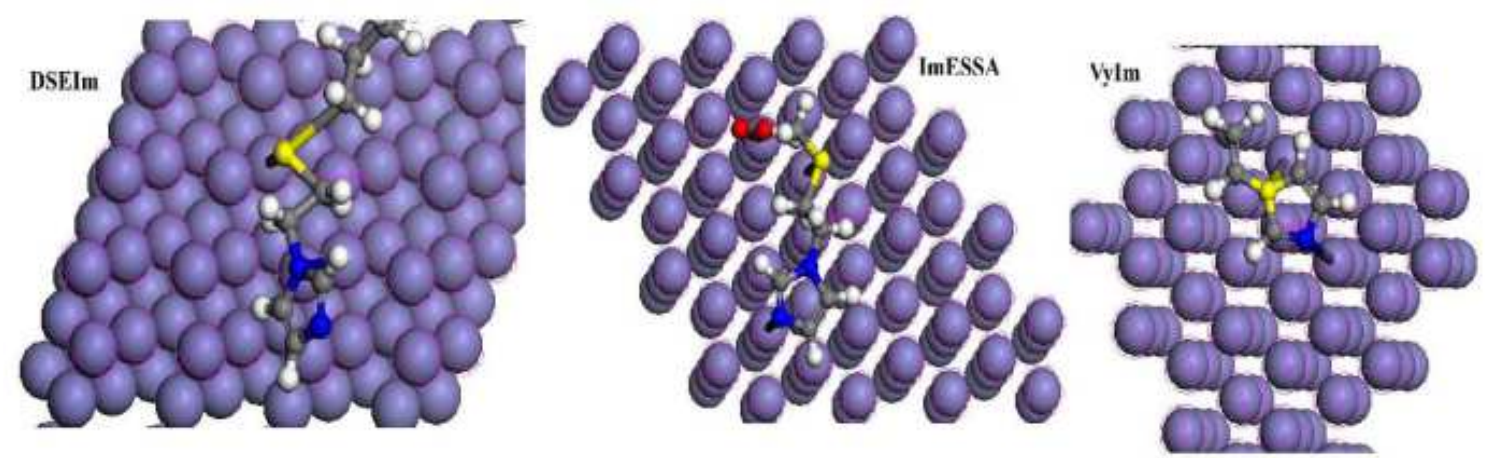

Figure 11. Equilibrium adsorption configuration of imidazole derivatives on Fe (111) surface obtained from molecular dynamics calculations.

The adsorption density of imidazole derivatives on the Fe (111) substrate is presented in Fig. 12 using Materials studio software.

As can be seen from Figs. 11 and 12 the imidazole derivatives molecules showthe ability to adsorb on a Fe (111) surface. Also, it has high binding energy to the Fe surface as seen in Table 5. 


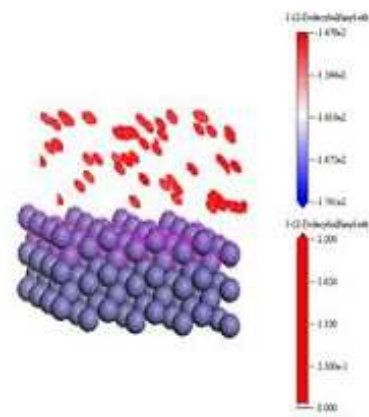

DSEIm

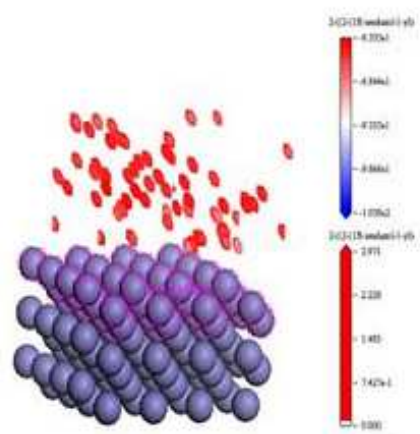

ImESAA

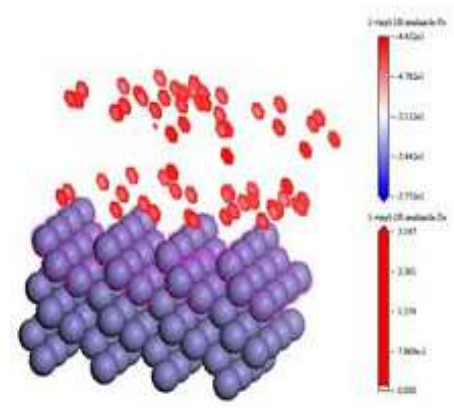

VyIm

Figure 12. Adsorption density field of imidazole derivatives on the $\mathrm{Fe}(111)$ substrate.

Table 5. Adsorption parameters of imidazole derivatives.

\begin{tabular}{|c|c|c|c|c|c|c|}
\hline Structures & $\begin{array}{c}\text { Total } \\
\text { Energy }\end{array}$ & $\begin{array}{c}\text { Adsorption } \\
\text { Energy }\end{array}$ & $\begin{array}{c}\text { Rigid Adsorption } \\
\text { Energy }\end{array}$ & $\begin{array}{c}\text { Deformation } \\
\text { Energy }\end{array}$ & $\begin{array}{c}\text { Imidazoles: } \\
\text { dEad/dNi }\end{array}$ & $\begin{array}{c}\text { Binding } \\
\text { energy }\end{array}$ \\
\hline DSEIm & -206.57 & -174.0799 & -178.7369 & 4.657 & -174.0799 & 197.32 \\
\hline ImESAA & - & -103.07 & -97.94 & -5.825 & -103.77 & 100.13 \\
\hline VyIm & $\begin{array}{c}115.324 \\
-\end{array}$ & -57.715 & -52.979 & -4.736 & -57.7158 & 49.68 \\
\hline
\end{tabular}

The outputs and descriptors calculated by the Monte Carlo simulation are presented in Table 5.

The parameters presented in Table 5 include total energy, in $\mathrm{kcal} \mathrm{mol}^{-1}$, of the substrate-adsorbate configuration. The total energy is defined as the sum of the energies of the adsorbate components, the rigid adsorption energy and the deformation energy. In this study, the substrate energy (iron surface) is taken as zero. In addition, adsorption energy in $\mathrm{kcal} \mathrm{mol}^{-1}$, reports energy released (or required) when the relaxed adsorbate components (imidazole derivatives in $\mathrm{HCl}$ ) are adsorbed on the substrate. The adsorption energy is defined as the sum of the rigid adsorption energy and the deformation energy for the adsorbate components. The rigid adsorption energy reports the energy, in $\mathrm{kcal} \mathrm{mol}^{-1}$, released (or required) when the unrelaxed adsorbate components (i.e., before the geometry optimization step) are adsorbed on the substrate. The deformation energy reports the energy, in $\mathrm{kcal} \mathrm{mol}^{-1}$, released when the adsorbed adsorbate components are relaxed on the substrate surface. Table 5 also shows that $\left(\mathrm{dE}_{\mathrm{ads}} / \mathrm{dNi}\right)$, which reports the energy, in kcal mol-1, of substrate-adsorbate configurations where one of the adsorbate components has been removed.

Fig. 13 shows the adsorption energy distribution of the imidazole derivatives on Fe (111). As can be seen in Fig. 13, the adsorption energy of DSEIm reaches ($\left.174 \mathrm{Kcal} \mathrm{mole}^{1}\right)$, ImESAA reaches $\left(-103.7 \mathrm{Kcal}^{-1} \mathrm{Col}^{-1}\right)$ and VyIm reaches $(-57.7$ Kcal mole ${ }^{-1}$ ) which shows the adsorption power for DSEIm molecules on Fe (111) surface. 

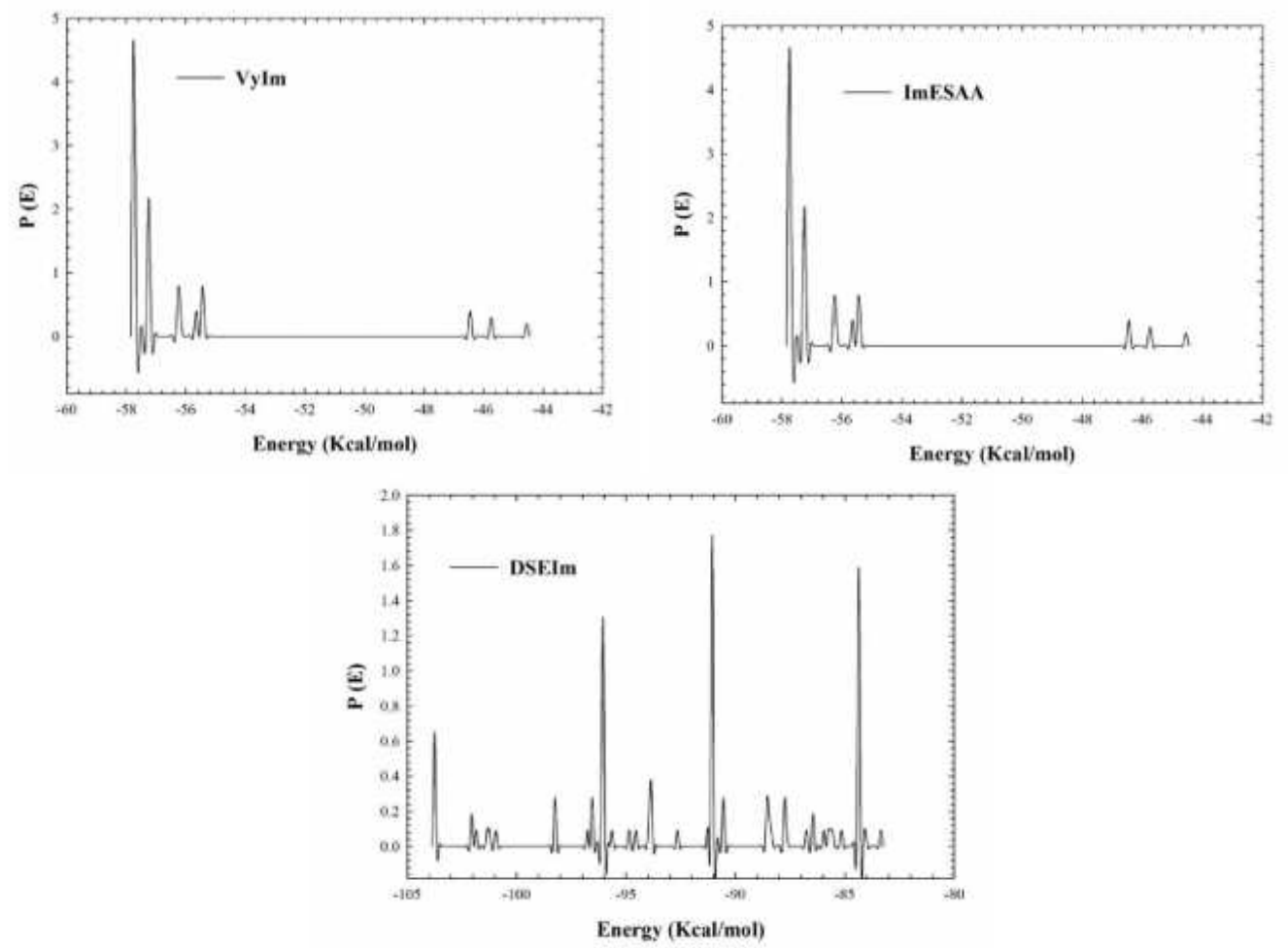

Figure 13. The adsorption energy distribution of the adsorbate (imidazole derivatives) on Fe (111) surface.

\section{Conclusions}

In this research, we have prepared various monoadducts with Telomerisation method based on 1-vinylimidazol, and have studied their corrosion inhibition properties as a function of concentration and temperature. The results can be summarized as follows.

1) DSEIm and ImESAA were synthesized by Telomerisation method, purified and characterized by ${ }^{1} \mathrm{HNMR}$ and ${ }^{13} \mathrm{CNMR}$ spectroscopy.

2) The monoadducts were evaluated for its inhibitive characteristics for mild steel in $1.0 \mathrm{M} \mathrm{HCl}$ by gravimetric and electrochemical methods, and it was found that all inhibitors could be used to protect the mild steel in $1.0 \mathrm{M} \mathrm{HCl}$. However, DSEIm is most suited to protect mild steel in acidic chloride environment.

3) Different results show that inhibition efficiency (\%E) increased with increasing inhibitor concentration, but decreased with temperature.

4) The increase of the alkyl chain length attached to the inhibitor molecule (DSEIm) increases its inhibition efficiency compared to at the presence of a functional group (ImESAA).

5) The trend of a greater inhibition efficiency with a higher temperature, and the increase in the activation energy in the presence of DSEIm, suggest a physical adsorption mechanism, although chemisorption may also play a part in the inhibiting process.

6) Monte Carlo simulation studies help to find the most stable imidazole derivative conformation and adsorption sites. This information can help to gain further insight into the corrosion system, such as the most likely point of attack 
for corrosion on a surface, the most stable site for inhibitor adsorption, adsorption density of the inhibitor and the binding energy of the adsorbed layer.

\section{References}

1. Solmaz R. Corros Sci. 2010;52:3321.

2. Srikanth AP, Lavanya A, Nanjundan S, et al. Appl Surf Sci. 2006;253:1810.

3. Cizek A. Mater Perform. 1994;33:56.

4. Batros M, Hakerman N. J Electrochem Soc. 1992;139:3429.

5. Kertit S, Hammouti B. Appl Surf Sci. 1996;93:59.

6. Zucchi F, Trabnelli G, Brunoro G. Corros Sci. 1992;33:1135.

7. Quraishi MA, Jamal D. Mater Chem Phys. 2001;71:202.

8. Quraishi MA, Ansari FA. J Appl Electrochem. 2006;36:309.

9. Rafiquee MZA, Kahn S, Saxena N, et al. Port Electrochim Acta. 2007;25:419.

10. Bentiss F, Traisnel M, Chaibi N, et al. Corros Sci. 2002;44:2271.

11. Lebrini M, Lagrenée M, Venzin H, et al. Corros Sci. 2005;47:485.

12. Emregül KC, Hayvali M. Mater Chem Phys. 2004;83:209.

13. Machnikova E, Whitmire KH, Hackerman N. Electrochim Acta. 2008;53:6024.

14. Ali SA, Al-Muallem HA, Saeed MT, et al. Corros Sci. 2008;50:664.

15. Ali SA, Saeed MT, Rahman SU. Corros Sci. 2003;45:253.

16. Yildırım A, Cetin M. Corros Sci. 2008;50:155.

17. Hassan HH, Abdelgahani E, Amin MA. Electrochim Acta. 2007;52:6359.

18. Khaled KF. Electrochim Acta. 2008;53:3484.

19. Lebrini M, Traisnel M, Lagrenée M, et al. Corros Sci. 2008;50:473.

20. Rammelt U. Koehler S. Reinhard G. Corros Sci. 2008;50:1659.

21. Abd El-Maksoud SA, Fonda AS. Mater Chem Phys. 2005;93:84.

22. Obi-Egbedi NO, Obot IB, Eseola AO. Arab J Chem. 2014;7:197.

23. Ergun U, Yuzer D, Emreguel KC. Mater Chem Phys. 2008;109:492.

24. Bentiss F, Lebrini M, Vezin H, et al. Mater Chem Phys. 2004;87:18.

25. Lebrini M, Bentiss F, Venzin H, et al. Corros Sci. 2006;48:1279.

26. Bentiss F, Traisnel M, Lagrenee M. Corros Sci. 2000;42:127.

27. Ramachandran S, Tsai B-L, Blanco M, et al. Langmuir. 1996;12:6419.

28. Villamizar W, Casales M, Martinez L, et al. J Solid State Electrochem. 2008;12:193.

29. Yoo SH, Kim YW, Chung K, et al. Corros Sci. 2012;59:42.

30. Tuken T, Demir F, Kicir N, et al. Corros Sci. 2012;59:110.

31. Lagrenee M, Mernari B, Bouanis M, et al. Corros Sci. 2002;44:73.

32. Bentiss F, Traisnel M, Lagrenee M. Br Corros J. 2000;35:315.

33. Wang HL, Liu RB, Xin J. Corros Sci. 2004;46:2455.

34. SaliyanVR, Adhikari AV. Corros Sci. 2008;50:55.

35. Fouda AS, Ellithy AS. Corros Sci. 2009;51:868.

36. Abed Y, Arrar Z, Aouniti A, et al. J Chem Phys. 1999;95:1347.

37. Khaled KF, Sherik AM. Int J Electrochem. 2013;8:10022.

38. Khaled KF. J Solid State Electrochem. 2009;13:1743. 
39. Boyer C, Boutevin G, Robin JJ, et al. Polymer. 2004;45:7863.

40. Senhaji O, Robin J, Achchoubi M, et al. Macromol Chem Phys. 2004;205:951.

41. Ameduri B, Boutevin B, Guida-Pietrasanta F, et al. J Fluorine Chem. 2001;107:397.

42. Aouniti A, Hammouti B, Kertit S, et al. Bull Electrochem. 1998;14:193.

43. Anuradha K, Vimala R, Narayanasamy B, et al. Chem Eng Comm. 2008; $195: 352$.

44. Obot LB, Obi-Egbedi NO. Curr Appl Phys. 2011;5:382.

45. Soltani N, Behpour M, Ghoreishi SM, et al. Corros Sci. 2010;52:1351.

46. Behpour M, Ghoreishi SM, Gandomi-Niasar A, et al. J Mater Sci. 2009;44:2444.

47. Solmaz R, Kardas G, Yazici B, et al. Colloids Surf A: Physicochem Eng Asp. 2008;312:7.

48. J. Barriga, B. Coto, B. Fernandez, Tribol. Int., 40 (2007) 960

49. Khaled KF. J Electrochem Soc. 2010;157:C116-C124.

50. Khaled KF. J Solid State Electrochem. 2009;13:1743

51. Khaled KF. J Appl Electrochem. 2011;41:423.

52. Khaled KF, Al-Mobarak NA. Int J Electrochem Sci. 2012;7:1045.

53. Khaled KF, Abdelshafi NS, Elmaghraby AA, et al. Int J Electrochem Sci. 2012;7:12706

54. Khaled KF, Abdel-Shafi NS. Int J Electrochem Sci. 2011;6:4077.

55. Khaled KF, Abdel-Shafi NS, Al-Mobarak NA. Int J Electrochem Sci.2012;7:1027.

56. Khaled KF. Electrochim Acta. 2008;53:3484.

57. Tan Y. Corros Sci. 2011;53:1845.

58. Tamura H. Corros Sci. 2008;50:1872.

59. Soares CG, Garbatov Y, Zayed A, et al. Corros Sci. 2008;50:3095.

60. Gudze MT, Melchers RE. Corros Sci. 2008;50:3296.

61. Accelrys to Release Enhanced Suite of Chemicals and Materials Modeling and Simulation Tools with Materials Studio(R) 4.1. in: Business Wire. New York; 2006. pp 0-n/a.

62. Ermer O. Calculation of molecular properties using force fields. Applications in organic chemistry. in: Bonding forces. Vol. 27. Berlin Heidelberg: Springer, 1976. Pp 161-211.

63. Khaled KF. Appl Surf Sci. 2008;255:1811. 